\title{
Quantifying sensitivity to droughts - an experimental modeling approach
}

\author{
M. Staudinger ${ }^{1}$, M. Weiler ${ }^{2}$, and J. Seibert ${ }^{1,3}$ \\ ${ }^{1}$ Department of Geography, University of Zurich, Zurich, Switzerland \\ ${ }^{2}$ Chair of Hydrology, University of Freiburg, Freiburg, Germany \\ ${ }^{3}$ Department of Earth Sciences, Uppsala University, Uppsala, Sweden
}

Correspondence to: M. Staudinger (maria.staudinger@geo.uzh.ch)

Received: 29 June 2014 - Published in Hydrol. Earth Syst. Sci. Discuss.: 9 July 2014

Revised: 16 February 2015 - Accepted: 23 February 2015 - Published: 12 March 2015

\begin{abstract}
Meteorological droughts like those in summer 2003 or spring 2011 in Europe are expected to become more frequent in the future. Although the spatial extent of these drought events was large, not all regions were affected in the same way. Many catchments reacted strongly to the meteorological droughts showing low levels of streamflow and groundwater, while others hardly reacted. Also, the extent of the hydrological drought for specific catchments was different between these two historical events due to different initial conditions and drought propagation processes. This leads to the important question of how to detect and quantify the sensitivity of a catchment to meteorological droughts. To assess this question we designed hydrological model experiments using a conceptual rainfall-runoff model. Two drought scenarios were constructed by selecting precipitation and temperature observations based on certain criteria: one scenario was a modest but constant progression of drying based on sorting the years of observations according to annual precipitation amounts. The other scenario was a more extreme progression of drying based on selecting months from different years, forming a year with the wettest months through to a year with the driest months. Both scenarios retained the observed intra-annual seasonality for the region. We evaluated the sensitivity of 24 Swiss catchments to these scenarios by analyzing the simulated discharge time series and modeled storage. Mean catchment elevation, slope and area were the main controls on the sensitivity of catchment discharge to precipitation. Generally, catchments at higher elevation and with steeper slopes appeared less sensitive to meteorological droughts than catchments at lower elevations with less steep slopes.
\end{abstract}

\section{Introduction}

Meteorological droughts such as the summer drought of 2003 (Rebetez et al., 2006) or the spring drought of 2011 (Kohn et al., 2014) in Europe caused low water levels in lakes, rivers and groundwater. Generally, a prolonged lack of precipitation (meteorological drought), storage of precipitation as snow or a strong deficit in the climatic water balance can propagate through the hydrological system causing soil moisture drought and hydrological drought (Tallaksen and Van Lanen, 2004; Mishra and Singh, 2010). The consequences of such droughts are challenging: water-use restrictions have to be applied to, for instance, energy production or irrigation. Water quality can be affected by faster warming of less than the usual water and reduced dilution, which in turn becomes an issue for the ecology and for the drinking water supply. Droughts like those in 2003 and 2011 are predicted to become more frequent in the future (Solomon, 2007), which calls for a better understanding of the response of different systems to droughts. Focusing on single processes in one catchment allows for a detailed analysis of the occurrence of different processes during an individual drought event (Santos et al., 2007; Trigo et al., 2010; Li et al., 2010). However, there are not enough observations of historical drought events to perform such a detailed analysis for several events and catchments with resulting detailed links between cause and effect. Historical droughts usually differ in initial conditions regarding the general preceding wetness and often additionally different occurrences in time and space, which makes a spatial and temporal analysis extremely challenging. A meteorological drought can develop 
into a hydrological drought through different mechanisms that are controlled by catchment characteristics as well as climate (Eltahir and Yeh, 1999; Peters et al., 2003; Tallaksen and Van Lanen, 2004; Van Loon and Van Lanen, 2012): several consecutive meteorological droughts can turn into a combined and prolonged hydrological drought and they can be attenuated by the storage of a catchment. Furthermore, a time lag between meteorological, soil moisture and hydrological droughts affects both streamflow and groundwater (Van Loon and Van Lanen, 2012). In addition to a deficit in precipitation, ice and snow acting as temporary storage can also cause droughts (Van Loon et al., 2010). Observed droughts reflect the diversity of drought processes which led to varyingly strong responses to meteorological droughts in different regions and catchments. Based on the various drought-generating mechanisms, Van Loon and Van Lanen (2012) developed a general hydrological drought typology and distinguished between six different drought types that include the type of precipitation and air temperature conditions preceding the drought (classical rainfall deficit drought, rainto-snow-season drought, wet-to-dry-season drought, coldsnow-season drought, warm-snow-season drought, and composite drought).

Previous studies looked at historical droughts and tried to link the occurrence and temporal development of a drought with climate and catchment characteristics such as topography or geology (e.g., Stahl and Demuth, 1999; Zaidman et al., 2002; Fleig et al., 2006). Stahl and Demuth (1999) found that spatial and temporal variability of streamflow drought was influenced by the geographical and topographical location and the underlying geology. Periods of prolonged streamflow drought were linked with persistent occurrence of specific circulation patterns; however, temporal streamflow drought development could not be linked to observed climatic drought.

Many studies have used scenarios to estimate the impact of climate change on streamflow in general and some focus on droughts in particular (e.g., Wetherald and Manabe, 1999, 2002; Wang, 2005; Lehner et al., 2006). The usual approach is to use simulations of general circulation models or regional climate models (GCMs/RCMs) with plausible scenarios of greenhouse gas emissions to drive hydrological models. However, there are large uncertainties connected to the GCM and RCM simulations and the choice of bias correction method (Teutschbein and Seibert, 2012, 2013), and the range of resulting impacts is accordingly high. Wilby and Harris (2006) used different GCMs, emission scenarios, downscaling techniques and hydrological model versions to assess uncertainties in climate change impacts and found that the resulting cumulative distribution functions of low flow for the river Thames were most sensitive to uncertainties in climate change scenarios and downscaling. Instead of dealing with these large uncertainties, here we focus on systematic changes. Thus, scenarios that exclude the large sources of uncertainty (climate change scenarios and downscaling) are a straightforward way to investigate the different responses of catchments to droughts.

In this study we assess how sensitive different catchments are to meteorological droughts and whether this sensitivity can be linked to a specific type of catchment, classified by catchment characteristics. We aim to answer these questions using a modeling experiment with two different scenarios of progressively drier meteorological conditions, based on observations.

\section{Methods and data}

\subsection{Data}

We selected 24 Swiss catchments, which vary in area, mean catchment elevation, land cover and geology (Table 1). Only catchments with minor anthropogenic influence were selected, i.e., no catchments with dams, major water extractions or inflow of sewage treatment plants, to investigate the main natural underlying processes. The selected catchments have, if any, minimal glacier influence and have discharge stations of satisfactory precision during low flow. Daily discharge observations were provided by FOEN (2013a). Gridded temperature $\left({ }^{\circ} \mathrm{C}\right)$ and precipitation $(\mathrm{mm})$ data (Frei, 2013) available for Switzerland (MeteoSwiss, 2013) were averaged over each catchment and then used to force the hydrological model. The observation period for discharge data used in this study extended from 1993 to 2012, for the meteorological data from 1975 to 2012. Information about catchment area, mean catchment elevation, forested land cover, and slope were extracted from the digital elevation map of Switzerland ( $25 \mathrm{~m}$ resolution).

A hydrogeological productivity number, which is a measure of hydraulic conductivity and thickness of the aquifer, was derived from the hydrogeological map of Switzerland (Aviolat et al., 2004): first, features of the aquifers were classified as productivity (high, variable, low, very low). Then, we assigned a numeric value between 0 and 1 to each of these productivity classes (high: 1 , variable: 0.5 , low: 0.1 , very low: 0) and computed an area-weighted mean. In a second step we investigated the influence of the choice of the numeric values by calibrating the values of the productivity classes to maximize the correlation between area-weighted mean values and sensitivity measures (described in the following section). The calibration was conditioned so that values increased from low to high productivity.

\subsection{HBV modeling experiment}

We conducted the modeling experiment with the semidistributed conceptual HBV model (Bergström, 1995; Lindström et al., 1997), in the version HBV-light (Seibert and Vis, 2012). Each catchment consisted of several elevation zones of $100 \mathrm{~m}$. The HBV model uses different routines (Fig. 1) to simulate catchment discharge based on time series of daily 


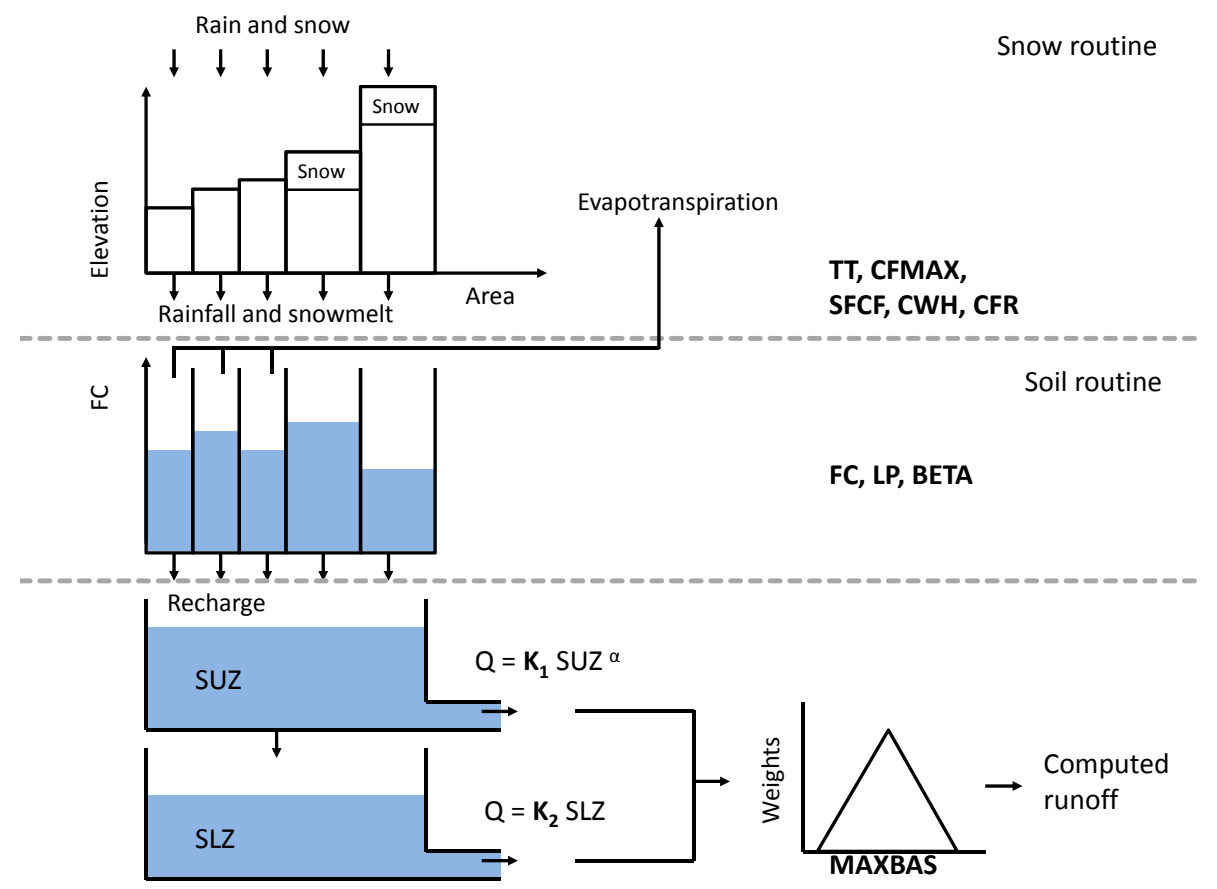

Figure 1. Structure of the HBV model.

precipitation and air temperature as well as estimates of longterm monthly potential evapotranspiration.

- Snow routine: snow accumulation and melt are computed by a degree-day method including snow water holding capacity and potential refreezing of meltwater.

- Soil routine: groundwater recharge and actual evaporation are simulated as functions of the actual water storage in the soil box. The soil moisture storage is called SM.

- Response routine: runoff is computed as a function of water storage in an upper and a lower groundwater box. The groundwater storage $(\mathrm{GW})$ from both groundwater boxes was summed.

- Routing routine: a triangular weighting function routes the runoff to the outlet of the catchment.

Detailed descriptions of the model can be found elsewhere (Bergström, 1995; Lindström et al., 1997; Seibert, 1999). The HBV-light model was calibrated automatically for each of the catchments over the period 1993-2012 using a genetic optimization algorithm with subsequent steepest gradient tuning (Seibert, 2000). Parameter uncertainty was addressed by performing 100 calibration trials, which resulted in 100 optimized parameter sets according to a combination of Nash-Sutcliffe model efficiency and volume error $\left(F_{\mathrm{LS}}\right.$, Eq. 1; Lindström et al., 1997), where the weighting factor for the latter was set to 0.1 , as recommended by Lindström et al.
(1997) and Lindström (1997). $F_{\mathrm{LS}}$ ranges between $-\infty$ for poor fits and 1 for a perfect fit,

$$
F_{\mathrm{LS}}=1-\frac{\sum\left(Q_{\mathrm{obs}}-Q_{\mathrm{sim}}\right)^{2}}{\sum\left(Q_{\mathrm{obs}}-{\overline{Q_{\mathrm{obs}}}}^{2}\right.}-0.1 \frac{\sum\left|\left(Q_{\mathrm{obs}}-Q_{\mathrm{sim}}\right)\right|}{\sum Q_{\mathrm{obs}}} .
$$

One simulation was run per parameter set over the entire meteorological observation period. The simulation results of this ensemble (100 selected parameter sets) were averaged at each time step to derive the reference simulation. The same was done for the scenarios. Each model simulation was preceded by a 1-year warm up period.

\subsection{Construction of the scenarios}

We constructed two precipitation time series as purely hypothetical scenarios, over the period 1975-2012, with progressively drying conditions.

- Scenario with sorted years (SoYe): all years over the meteorological observation period were sorted from the wettest to the driest year according to the total annual precipitation. Thus, a scenario of modest but continuous progression of drying was derived.

- Scenario with sorted months (SoMo): for this scenario we shuffled the individual months, with the wettest January together with the wettest February and so on, forming the first year. The second-wettest individual calendar months composed the second year. With this approach a scenario was created with a continuous pro- 
Table 1. Catchment characteristics (FOEN, 2013b) and calibration results; the catchments are sorted by mean catchment elevation. $F_{\mathrm{LS}}$ is the model efficiency (Eq. 1).

\begin{tabular}{|c|c|c|c|c|c|c|c|}
\hline Number & River & $\begin{array}{l}\text { Area } \\
\left(\mathrm{km}^{2}\right)\end{array}$ & $\begin{array}{r}\text { Mean } \\
\text { elevation } \\
\text { (m a.s.l.) }\end{array}$ & $\begin{array}{l}\text { Regime type } \\
(-)\end{array}$ & $\begin{array}{l}\text { Productivity* } \\
(-)\end{array}$ & $\begin{array}{c}\text { Forest } \\
(\%)\end{array}$ & $\begin{array}{c}\text { Range } F_{\mathrm{LS}} \\
(-)\end{array}$ \\
\hline 1 & Aach & 48.5 & 480 & pluvial & 0.27 & 0.33 & $0.79-0.82$ \\
\hline 2 & Ergolz & 261 & 590 & pluvial & 0.37 & 0.41 & $0.84-0.86$ \\
\hline 3 & $\mathrm{Aa}$ & 55.6 & 638 & pluvial & 0.24 & 0.22 & $0.82-0.84$ \\
\hline 4 & Murg & 78.9 & 650 & pluvial & 0.28 & 0.27 & $0.81-0.83$ \\
\hline 5 & Mentue & 105 & 679 & pluvial & 0.15 & 0.16 & $0.79-0.82$ \\
\hline 6 & Broye & 392 & 710 & pluvial & 0.23 & 0.23 & $0.80-0.81$ \\
\hline 7 & Langeten & 59.9 & 766 & pluvial & 0.36 & 0.19 & $0.70-0.74$ \\
\hline 8 & Rietholz & 3.3 & 795 & pluvial & 0.25 & 0.21 & $0.72-0.74$ \\
\hline 9 & Guerbe & 117 & 873 & pluvial & 0.33 & 0.33 & $0.78-0.80$ \\
\hline 10 & Biber & 31.9 & 1009 & pluvial & 0.23 & 0.41 & $0.82-0.84$ \\
\hline 11 & Kleine Emme & 477 & 1050 & nivo-pluvial & 0.21 & 0.35 & $0.82-0.82$ \\
\hline 12 & Ilfis & 188 & 1051 & nivo-pluvial & 0.24 & 0.46 & $0.78-0.81$ \\
\hline 13 & Sense & 352 & 1068 & pluvio-nival & 0.24 & 0.33 & $0.77-0.79$ \\
\hline 14 & Alp & 46.6 & 1155 & nivo-pluvial & 0.23 & 0.45 & $0.76-0.78$ \\
\hline 15 & Emme & 124 & 1189 & nival & 0.17 & 0.32 & $0.74-0.78$ \\
\hline 16 & Sitter & 261 & 1252 & nival & 0.08 & 0.22 & $0.73-0.74$ \\
\hline 17 & Erlenbach & 0.64 & 1300 & nivo-pluvial & 0.10 & 0.60 & $0.75-0.77$ \\
\hline 18 & Luempenen & 0.93 & 1318 & nivo-pluvial & 0.31 & 0.35 & $0.76-0.77$ \\
\hline 19 & Grande Eau & 132 & 1560 & nival & 0.21 & 0.33 & $0.79-0.81$ \\
\hline 20 & Schaechen & 109 & 1717 & nival & 0.29 & 0.16 & $0.90-0.92$ \\
\hline 21 & Allenbach & 28.8 & 1856 & nivo-glaciar & 0.10 & 0.13 & $0.73-0.76$ \\
\hline 22 & Riale di Calneggia & 24 & 1996 & nivo-pluvial & 0.26 & 0.07 & $0.80-0.82$ \\
\hline 23 & Ova da Cluozza & 26.9 & 2368 & nival & 0.47 & 0.05 & $0.73-0.78$ \\
\hline 24 & Dischma & 43.3 & 2372 & glacio-nival & 0.21 & 0.02 & $0.77-0.81$ \\
\hline
\end{tabular}

1 .

gression of drying in a more extreme manner than SoYe, but nevertheless keeping the natural seasonality.

The daily air temperature matching the precipitation from the original time series was rearranged in parallel to the precipitation scenarios; i.e., the observed temperature remained linked to the observed precipitation. For all scenarios the land cover was kept unchanged allowing one to focus on the sensitivity of response of streamflow by gradually drying out the catchment. The land cover also remained basically unchanged in the last 40 years in the studied catchments. These hypothetical scenarios showed the sensitivity of catchments to extreme drying conditions, particularly in relation to initial conditions (one dry year follows another). The scenarios allow one to further include observed weather conditions combined with drier than ever observed initial conditions, which are still based on observed preceding precipitation.

\subsection{Relative change to long-term conditions}

First, we looked at the relative change of each scenario year, $x_{i}$, to the long-term mean of the reference simulation, $\bar{x}$.

$\Delta x_{i}=\frac{x_{i}}{\bar{x}}$,

where $x$ stands for the variable of interest and $i$ the year. $\Delta x_{i}$ was calculated for simulated runoff $\left(Q_{\text {sim }}\right)$, simulated soil moisture storage (SM), and the combined simulated upper and lower groundwater storages $(\mathrm{GW}=\mathrm{SUZ}+\mathrm{SLZ})$ (Fig. 1; Eq. 2). Secondly, to assess the catchment sensitivity to the progression of drying we calculated the interquartile range (IQR) of all $\Delta x_{i}$. IQR represents the variability during the drying phase. Since the scenarios force progressive drying over the course of the years, IQR can be seen as a measure of sensitivity to droughts: the smaller the value of IQR, the less sensitive a catchment is to droughts, and the higher the value of IQR, the more sensitive a catchment is to droughts. This sensitivity results from both the local climate variability and modification by specific catchment characteristics. Since the construction of the scenarios was based on annual and 
Table 2. Spearman rank correlation coefficients between the catchment characteristics from Table 1. All correlations were significant at the $5 \%$ level (Prod. no. - productivity number).

\begin{tabular}{lcrrrr}
\hline & Elevation & Size & Slope & Prod. no. & Forest \\
\hline Elevation & 1.000 & -0.362 & 0.853 & -0.130 & -0.328 \\
Size & & 1.000 & -0.563 & -0.131 & 0.236 \\
Slope & & & 1.000 & 0.012 & -0.108 \\
Prod. no. & & & & 1.000 & -0.244 \\
Forest & & & & & 1.000 \\
\hline
\end{tabular}

monthly precipitation differences, we accounted for the relative influence of the interannual variability of precipitation in each catchment on the scenario. For each year the ratio between mean annual precipitation $P$ and long-term mean annual precipitation $\bar{P}$ was calculated (Fig. 2). This precipitation ratio was then used to account for the potential influence of the interannual precipitation variability. Each IQR was divided by the interquartile range of these precipitation ratios (Eq. 3) to minimize the influence of the local precipitation variability and to compare between the different catchments. The so modified IQR is referred to as $I_{\text {rel }}$.

$I_{\text {rel }}=\frac{\Delta x_{75}-\Delta x_{25}}{\frac{P}{\bar{P}} 75-\frac{P}{\bar{P}} 25}$

where $\Delta x_{75}$ is the 75th percentile of $\Delta x_{i}$ and $\Delta x_{25}$ the 25th percentile of $\Delta x_{i}$. Even though $I_{\text {rel }}$ includes both wet and dry years, it gives an overall impression of the response of a catchment to the progression of drying. We accounted for drought more specifically by comparing the extreme dry end of each scenario (driest year of both scenarios) with the long-term mean. The extreme end of each scenario was additionally compared to the driest year from the reference simulation in order to determine in which seasons the strongest effect of drying was found.

We looked at drought characteristics more specifically by counting the days per year that exceeded the 90th streamflow percentile $\left(Q_{90}\right)$ of the respective reference simulation (100 parametrizations). $Q_{90}$ is a commonly used threshold value to define hydrological drought periods. Again, we calculated a relative change (Eq. 2), here with $x$ being the number of days exceeding $Q_{90}$. We used days exceeding $Q_{90}$ instead of days below the threshold, to derive indices that are larger, when the sensitivity is higher. We used further indices that describe the influence of the progression of drying at its extreme dry end. These indices are the ratios of the difference between long-term mean and mean of the driest year of each scenario and the long-term mean $(\Delta Q$ Driest SoYe for scenario SoYe; $\Delta Q_{\text {Driest SoMo }}$ for scenario SoMo). As for the other indices, the larger $\Delta Q_{\text {Driest SoYe }}$ and $\Delta Q_{\text {Driest SoMo }}$ are, the more sensitive the respective catchments are to droughts.

Catchment controls on the sensitivity of catchments to droughts were investigated by correlations between specific catchment characteristics (Table 1) and sensitivities using

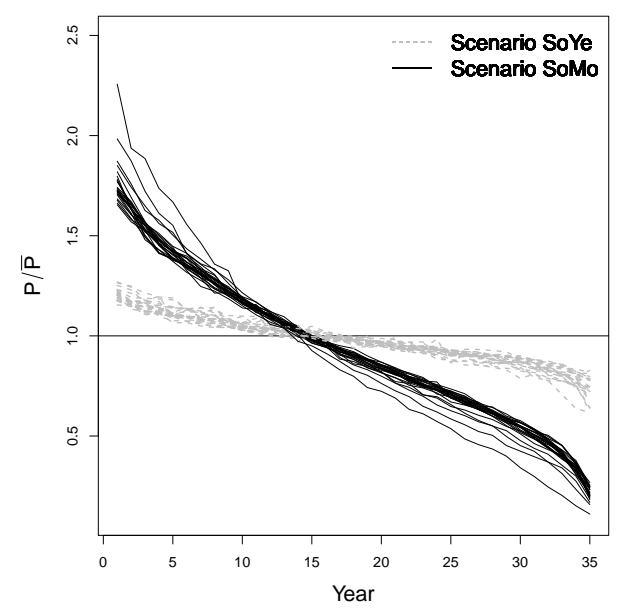

Figure 2. Precipitation ratios of the annual precipitations $P$ and the long-term mean precipitation $\bar{P}$ for scenarios SoYe and SoMo.

Spearman rank correlations. The significance of the correlations was evaluated using the $p$ value of the distributions, where correlations with a $p$ value of $<0.05$ were considered significant. An important aspect in such analyses are the correlations among catchment characteristics themselves, which can make an interpretation of correlations between catchment characteristics and sensitivities more difficult. For our catchments, even though there was a significant correlation between mean catchment elevation and slope (Table 2), the highest elevation catchments do not have the steepest slopes.

The influence of drier initial conditions was highlighted in a further simulation experiment based on scenario SoMo. We chose the drought in 2003 because it was one of the recent serious summer droughts that affected all studied catchments and this summer drought had a normal preceding winter, i.e., normal snow conditions. Recent droughts in spring (e.g., 2011, 1976) were not analyzed more specifically, as these droughts had already particularly dry initial conditions. For this simulation experiment, we used the last years of the scenario SoMo up to the end of May followed by the actual series of summer 2003 starting from 1 June. In this way we simulated how much more each catchment would have been affected if the preceding months to the 2003 drought event would have been drier than actually observed. For all catchments a further index was calculated describing the sensitivity of the catchments to drier initial conditions and thus also to droughts by dividing the mean of the SoMo scenariobased simulation with the drier initial conditions for the summer months of 2003 (June-August) by the mean of the reference simulation for the same months. This index was called $\Delta Q_{2003}$ for $Q_{\text {sim }}, \Delta \mathrm{SM}_{2003}$ for SM, and $\Delta \mathrm{GW}_{2003}$ for $\mathrm{GW}$. The larger these indices are, the more sensitive the respective catchments are to droughts.

The sensitivity of the catchments, as described by the introduced indices, was further analyzed with regard to the role of snow therein. The question was, how much of the sensitiv- 


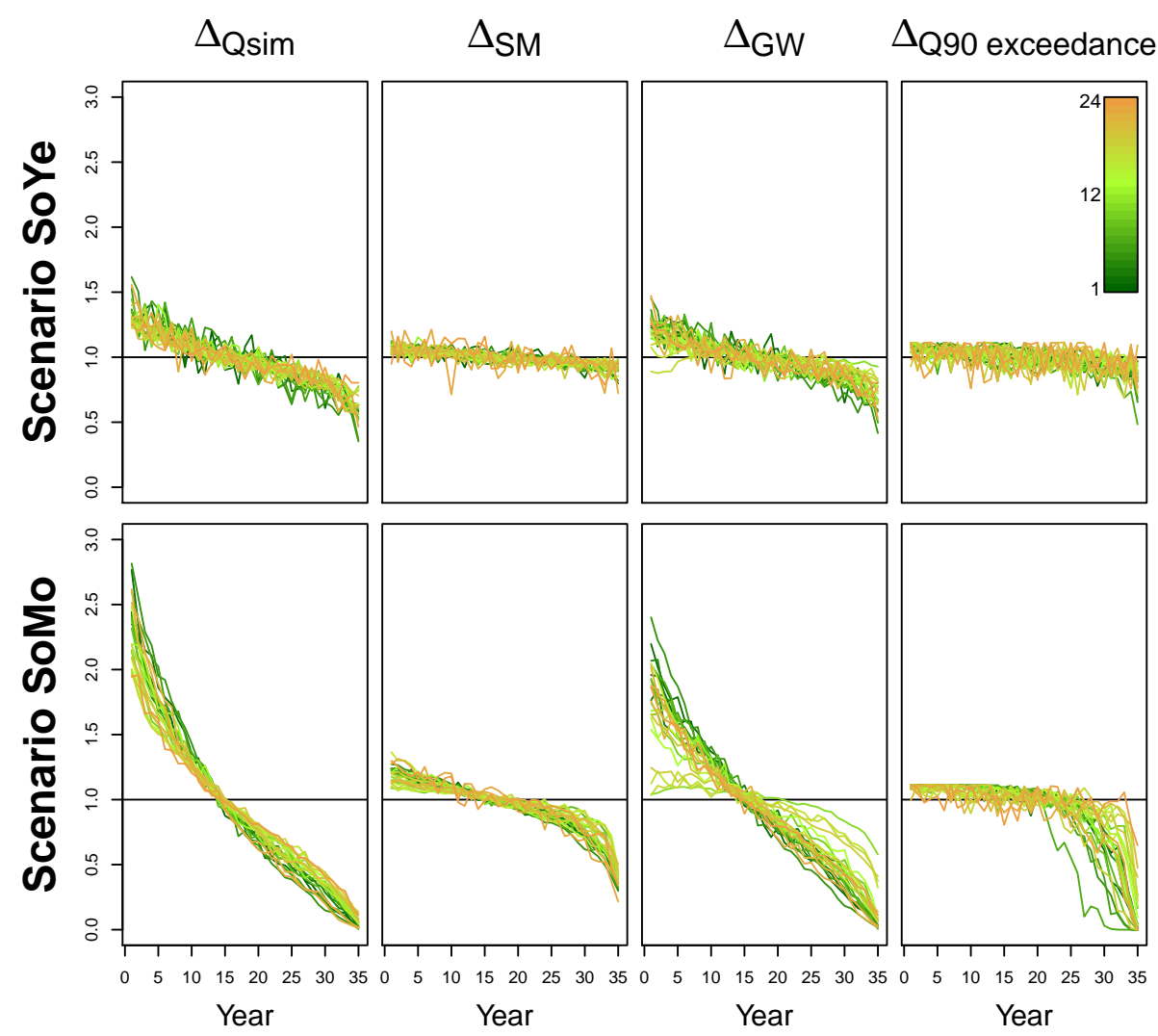

Figure 3. Relative change of $Q_{\text {sim }}, \mathrm{SM}$ and GW and the $Q_{90}$ exceedance days for the two scenarios to the long-term reference for all catchments. Each color stands for one catchment number (Table 1), where the greener colors indicate catchments at the lower mean elevation and the more brownish colors were used for catchments at higher mean elevation. Note that the upper boundary of the relative change of $Q_{90}$ is given by the fixed days that are exceeding $Q_{90}$ per year and the maximum days per year.

ity could be attributed to snow storage. We investigated this by simulating all precipitation as rain (i.e., no snow accumulation) using the same parameter sets derived by the calibration and repeating the scenario analyses described above.

\section{Results}

\subsection{Interannual variation}

All catchments could be calibrated satisfactorily with median $F_{\text {LS }}$ values (Eq. 1) ranging between 0.73 and 0.92 (Table 1). The relative change of the different variables clearly indicated a progression of drying of streamflow as well as of the storages, where the relative change of the continuous drying for all catchments was smallest for the SM of both scenarios (Fig. 3).

The SoMo scenario generally resulted in stronger responses to the drying and the relative changes specific for the different catchments became more pronounced than in scenario SoYe. During wetter conditions than the long-term mean, the $\Delta_{Q_{\text {sim }}}$ values were larger for the higher elevation catchments compared to lower elevation catchments. During drier conditions than the long-term mean, the $\Delta_{Q_{\text {sim }}}$ values were smaller for the higher elevation catchments compared to lower elevation catchments. This indicates that during wet conditions the high elevation catchments were more sensitive to the progressive drying; however, during dry conditions high elevation catchments were less sensitive to the drying compared to lower elevation catchments. The same can also be seen for $\Delta_{\mathrm{GW}}$ where the change from wetter to drier conditions relative to the long-term GW mean shows more variability between the catchments than $\Delta_{Q_{\text {sim }}}$ (Fig. 3).

The general behavior at the end of the scenarios was illustrated using four of the catchments by comparing the longterm mean and the driest year of the reference simulation (in terms of precipitation) (Fig. 4). Scenario SoYe resulted, most of the time, in streamflow values below the long-term mean. However, the scenario did not always result in lower streamflow values compared to the long-term mean. For the nival catchments (Ilfis, Sitter, Emme) the hydrograph from SoYe was below the long-term mean streamflow during the spring flood as well as during late summer. The difference between long-term mean streamflow and the streamflow from scenario SoYe varied remarkably between the catchments. The overall difference between the long-term mean and the 

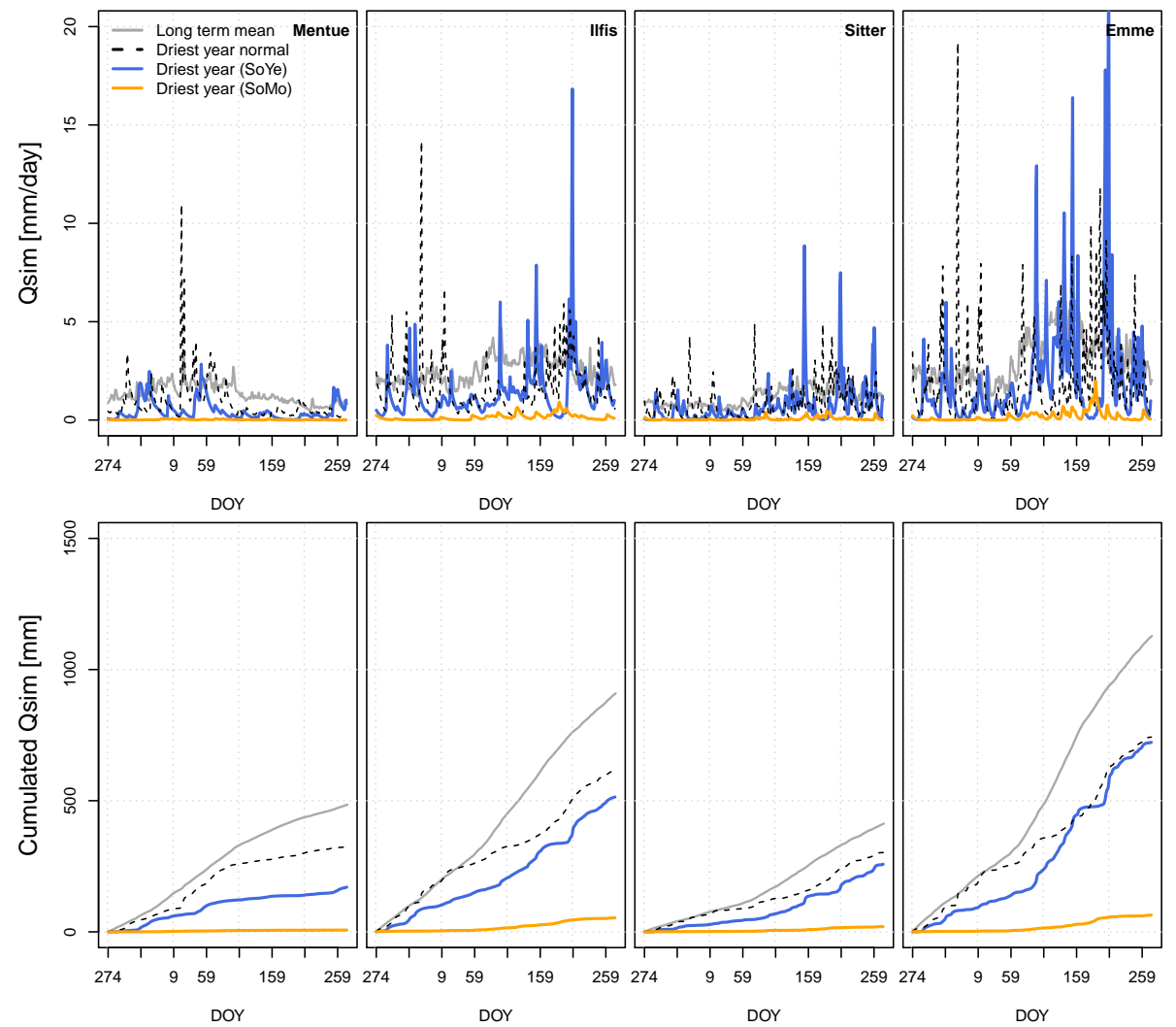

Figure 4. $Q_{\text {sim }}$ and cumulated $Q_{\text {sim }}$ for long-term mean, driest year of the reference simulation as well as the driest years of the two scenarios for four example catchments.

scenario SoYe (cumulative sums) confirms the variation between the catchments and thus the variation in their sensitivity to continuous drying (Fig. 4). The difference between the last year's SoYe and the driest year of the reference simulation was minor and resulted from the different initial conditions caused by the preceding summer. The driest year of scenario SoMo resulted for each day in streamflow values below the long-term mean, the driest year of the reference simulation and the driest year of the SoYe scenario for all catchments. The discharge of the pluvial Mentue catchment was nearly 0 in the driest year of scenario SoMo. For the catchments with some snow influence, there remained periods of higher streamflow in spring and summer, however, with a very reduced spring flood as compared to the SoYe scenario or the reference. For the scenario SoMo, the cumulative sums show that the annual difference between long-term mean and the scenario varies among the different catchments.

\subsection{Low flow frequency}

The frequency of days exceeding the $Q_{90}$ threshold changed only little for the SoYe scenario (Fig. 3) compared to the long-term mean. Even though over the course of the years a slight decrease of days exceeding $Q_{90}$ could be noticed, there were still years at the end of the scenario that had more exceeding days than the long-term mean. For the SoMo scenario, however, there was a strong decrease in days exceeding $Q_{90}$ with the progression of drying. In this scenario the difference between the catchments also became apparent: in the relatively wetter years, the lower elevation catchments already started to have less days above the threshold; i.e., they were more vulnerable to droughts. In the medium dry years of the scenario, the higher elevation catchments also showed less days above the threshold compared to the long-term mean. The highest elevation catchments followed in even drier years of the scenario to show less days above the threshold compared to the long-term mean. In scenario SoMo, the highest elevation catchments show a clear decrease in days exceeding $Q_{90}$ at the dry end of the scenario.

\subsection{Initial conditions}

The historical drought event of the summer 2003 and how it would have changed with different initial conditions for the different catchments is shown for the four example catchments (Fig. 5). While for the Mentue, Ilfis and Sitter catchments the influence of the drier initial conditions can be seen relatively long into the summer months, for the Emme catchment, this memory is comparably short. However, looking at the storages SM and GW for the reference simulation as well 


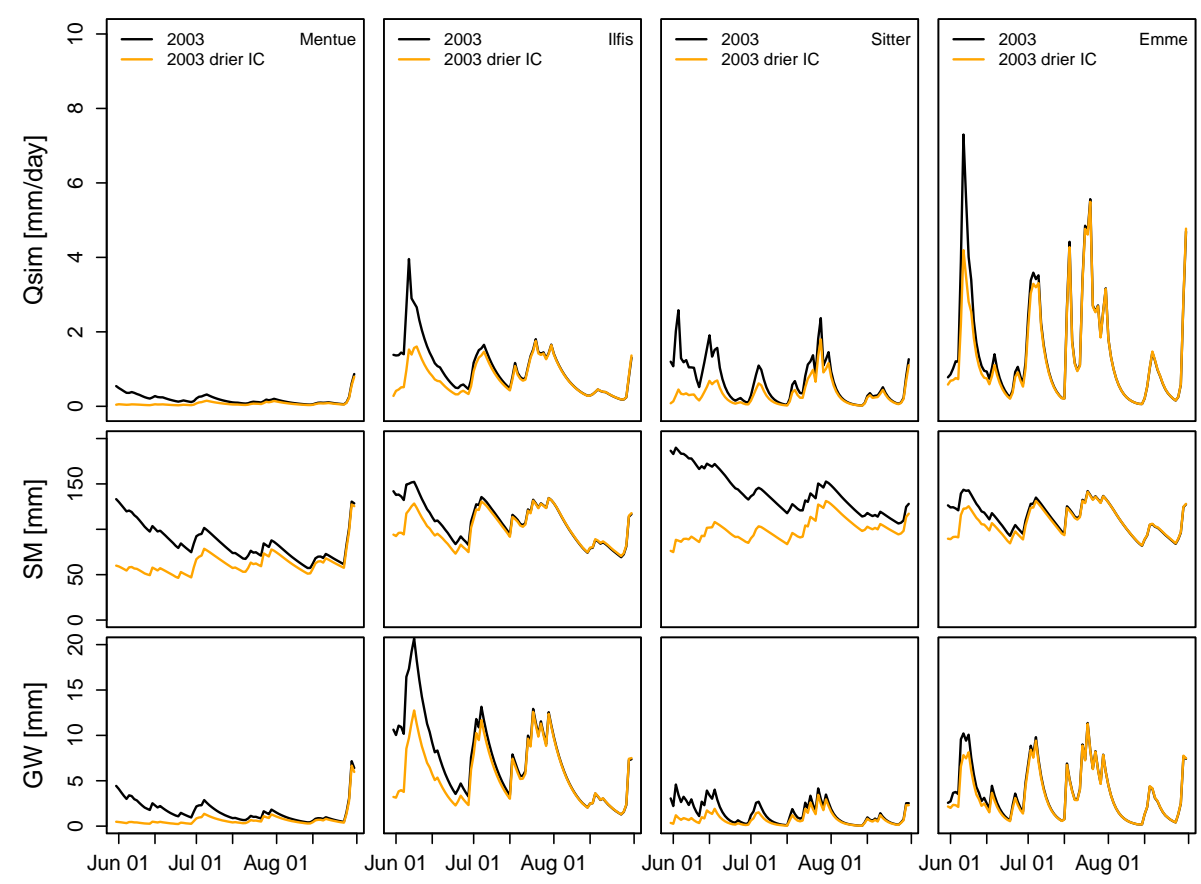

Figure 5. Simulation (median of 100 simulations) of the summer drought 2003, original and with drier initial conditions (IC).

as the simulation with drier initial conditions shows that the causes for longer or shorter influence are not the same for the different catchments: the important storage for the effect of the initial conditions for Mentue and Ilfis is composed of both storages, while for the Sitter and the Emme catchments SM seems to be stronger and more important longer than for GW.

\subsection{Importance of catchment characteristics}

The $I_{\text {rel }}$ values of $Q_{\text {sim }}$ were significantly correlated with catchment mean elevation, size and slope, respectively (Fig. 6). Mean catchment elevation and drought sensitivity were negatively correlated, i.e., higher mean catchment elevations were related to lower drought sensitivities. Steeper slopes are also related to lower drought sensitivities. For SM the $I_{\text {rel }}$ values were significantly correlated with size and slope, while for GW the IQR values were correlated with mean catchment elevation and slope. The percentage of forested area had no significant influence on the sensitivity of the catchments to droughts, while the hydrogeological productivity numbers were only significantly correlated with the IQR of days exceeding $Q_{90}$ (Fig. 6). A summary of all indices can be found in Table 3. The drought-targeting indices (IQR of days exceeding $Q_{90}, \Delta Q_{\text {Driest SoYe }}, \Delta Q_{\text {Driest SoMo, }}$ and changes of summer 2003 with drier initial conditions $\Delta Q_{2003}, \Delta \mathrm{SM}_{2003}$ and $\left.\Delta \mathrm{GW}_{2003}\right)$ could also be related to the catchment characteristics (Fig. 7); most of them were correlated with size, elevation or slope of the catchment: IQR of days exceeding $Q_{90}$ as well as $\Delta Q_{2003}$ were significantly correlated with size and slope of the catchment. The ratios of the driest years of the two scenarios $\Delta Q_{\text {Driest SoYe }}$ and $\Delta Q_{\text {Driest SoMo }}$ were significantly correlated with size and elevation, respectively. $\Delta \mathrm{SM}_{2003}$ was correlated with mean elevation, slope and size of the catchment.

The correlation between hydrogeology (expressed in productivity numbers) and drought sensitivity was influenced by the choice of the numeric values of the productivity classes. The correlation between hydrogeology and drought sensitivity could be increased from non-significant correlations to ( $p$ value $>=0.05$ ) Spearman rank correlation coefficients of 0.53 . The correlation that existed between productivity number and days exceeding $Q_{90}$ could be increased to 0.5 compared to 0.4 of the originally assigned values for each productivity class. The values for the productivity classes after calibration to the different drought sensitivity indicators were high $(0.79-0.97)$, variable $(0.29-0.6)$, low $(0.22-0.24)$ and very low $(0.02-0.22)$.

\subsection{Role of snow}

Repeating the scenario simulations with rain instead of snow resulted in only minor changes of the sensitivities of the catchments (Fig. 8). For $I_{\text {rel }} Q_{\text {sim }}$, the higher catchments were slightly more sensitive to the progressive drying without snow storage; however, the change in sensitivity was not systematically increasing with the percentage of snow observed in the catchments. The changes in $I_{\text {rel }} \mathrm{GW}$, $I_{\text {rel }} \mathrm{SM}$ and IQR of days exceeding $Q_{90}$ when simulating no snow were similar, with higher elevation catchments being 

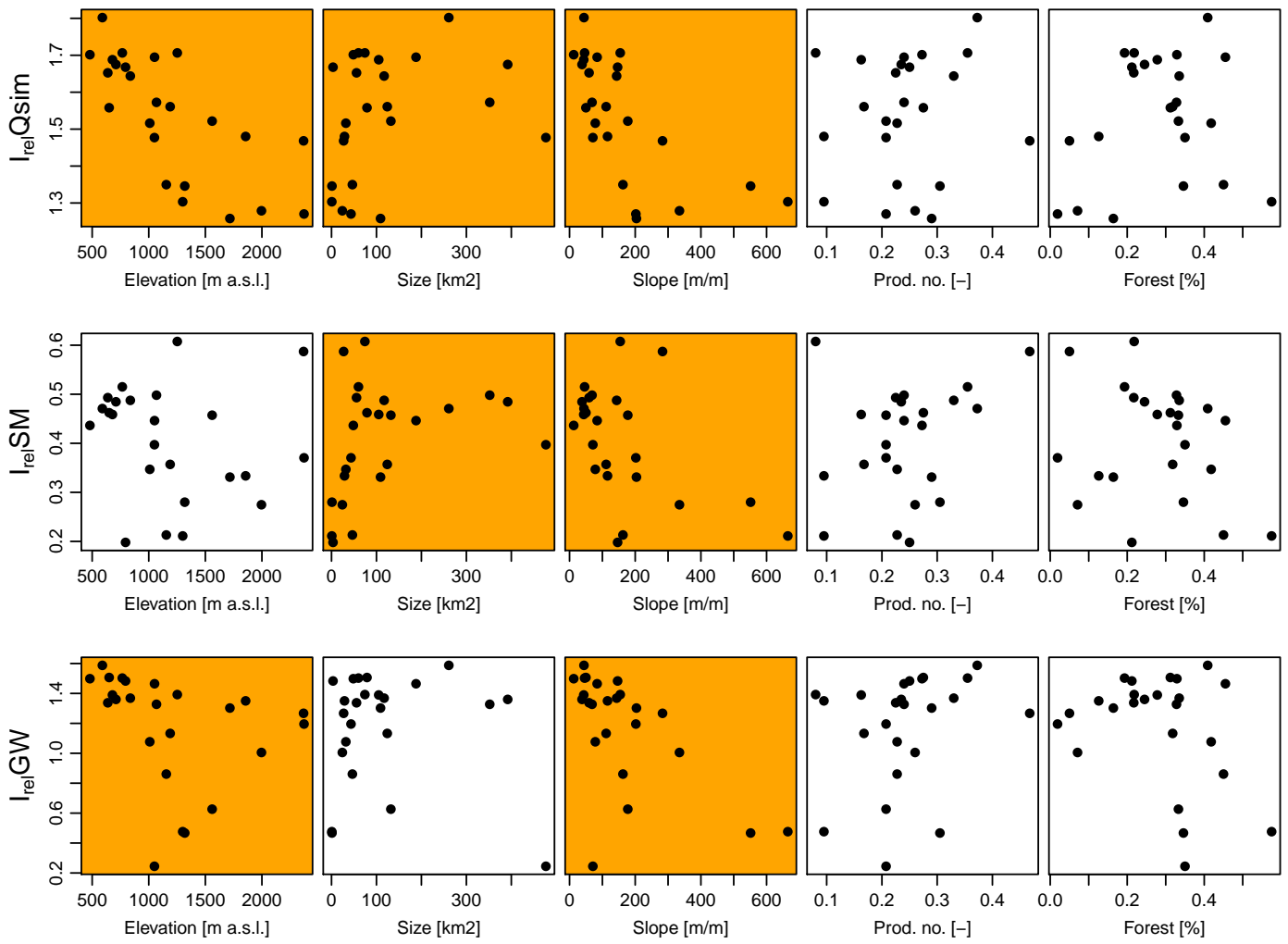

Figure 6. $I_{\text {rel }}$ for $Q_{\text {sim }}, \mathrm{SM}$, and GW compared to simple catchment characteristics. The orange background indicates a significant correlation ( $5 \%$ level) between the respective $I_{\text {rel }}$ and catchment characteristic. Prod. no. is the hydrogeological productivity number as introduced in Sect. 2.1.

more sensitive without snow. However, for $\Delta Q_{\text {Driest SoYe }}$ and $\Delta Q_{\text {Driest SoMo }}$ there are very small changes in sensitivity for all catchments in both directions without obvious systematic character.

\section{Discussion}

\subsection{Sensitivity to progressive drying}

We looked at the effects of the continuous progression of drying on the different catchments and found that, in general, even modest drying led to a continuous reduction of streamflow, soil moisture and groundwater storage on the one hand and on the other hand the moderate scenario already revealed catchments that were more sensitive to droughts than others. With the more extreme scenario the picture became even clearer. However, for the drought's characteristic duration of days exceeding $Q_{90}$, only the more extreme scenario showed a clear effect. The driest year of the moderate scenario showed seasons with lower than the long-term mean streamflow values, which differed for catchments with different streamflow regimes. The lower elevation catchments had a long, dry summer and fall. In the higher elevation catchments there were again higher streamflow values in late sum- mer, which could be explained by a filling of the storages in spring. Snowmelt water could fill the storages more than it would be possible if it was only rainfed (at least in the temperate humid climate of Switzerland). Other differences between the catchments with nival regimes have then to be accounted for by different storage release characteristics. This could be confirmed by the analysis of the historical drought in the summer of 2003 compared to a scenario with drier initial conditions as the storages for the different catchments contributed in different proportions to the reduced streamflow under drier initial conditions.

The relative differences were small, but the initial conditions can have noticeable impacts even when looking at a whole year. The differences due to initial conditions varied between about 50 and $80 \%$, which is in the same order of magnitude as what might be expected due to climate change (e.g., Lettenmaier et al., 1999; Nijssen et al., 2001).

Comparing the drought sensitivities to catchment characteristics revealed that for both streamflow $\left(I_{\text {rel }}\right)$ as well as duration of days above the $Q_{90}$ threshold mean catchment elevation, size and slope were the main controls. Kroll et al. (2004), who tested different catchment characteristics as to their suitability to improve the regionalization of low flows in the US, found that signatures describing hydrogeology, slope and size and also elevation were important and im- 

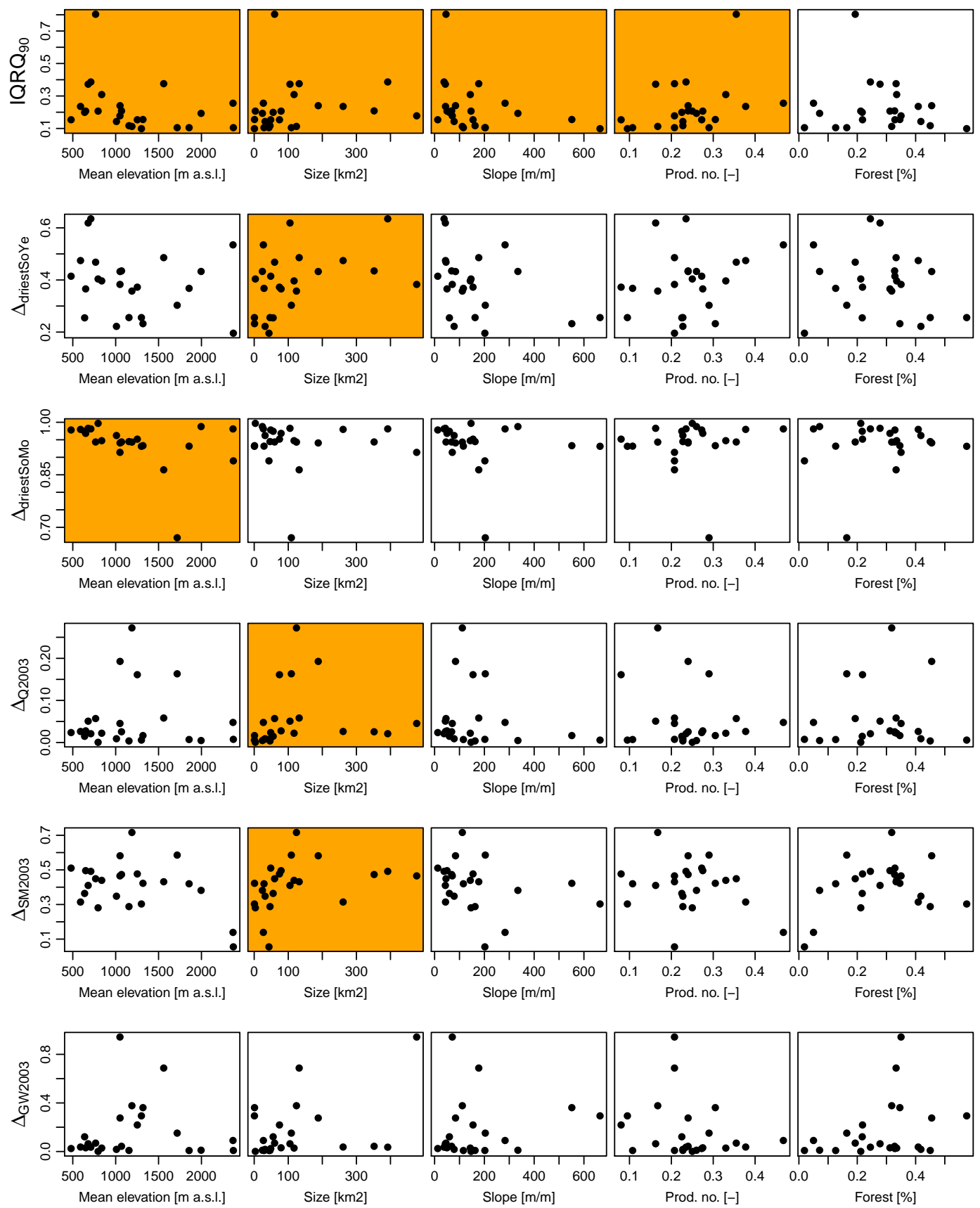

Figure 7. Indicators to drought sensitivity: days above the threshold $Q_{90}, \Delta Q_{\text {Driest SoYe }}, \Delta Q_{\text {Driest SoMo, and changes of summer } 2003 \text { with }}$ drier initial conditions $\Delta Q_{2003}, \Delta \mathrm{SM}_{2003}$ and $\Delta \mathrm{GW}_{2003}$ compared to simple catchment characteristics. The orange background indicates a significant correlation (5\% level) between the respective indicator and catchment characteristic. Prod. no. is the hydrogeological productivity number as introduced in Sect. 2.1.

proved low flow, regional regression models. However, while size was an important predictor for almost every region they investigated, elevation improved low flow prediction only in a few regions of the US. For soil moisture storage only size and slope control drought sensitivity and for groundwater storage only elevation and slope control drought sensitivity. Streamflow showed all the controls of the storages. The fact that mean catchment elevation is important for drought sensitivity in streamflow can be partly explained by snow at higher elevations. The investigation of the direct role of snow showed that only for some indicators is the sensitivity snowdependent. Some sensitivity indicators, particularly looking at the drought characteristics did not change with a no-snowsimulation. Snow influenced sensitivities but cannot explain 
Table 3. Drought indicators for all catchments. The smaller the value the less sensitive the catchment is to drying.

\begin{tabular}{lrrrrrrrrr}
\hline Catchment & $I_{\text {rel }} Q_{\text {sim }}$ & $I_{\text {rel SM }}$ & $I_{\text {rel GW }}$ & $\mathrm{IQR}_{Q_{90}}$ & $\Delta Q_{2003}$ & $\Delta \mathrm{SM}_{2003}$ & $\Delta \mathrm{GW}_{2003}$ & $\Delta Q_{\text {driest SoYe }}$ & $\Delta Q_{\text {driest SoMo }}$ \\
\hline Aach & 1.701 & 0.436 & 1.499 & 0.154 & 0.024 & 0.511 & 0.025 & 0.719 & 1.282 \\
Ergolz & 1.802 & 0.471 & 1.588 & 0.236 & 0.026 & 0.315 & 0.037 & 0.737 & 1.242 \\
Aa & 1.653 & 0.493 & 1.338 & 0.199 & 0.015 & 0.364 & 0.120 & 0.848 & 1.567 \\
Murg & 1.558 & 0.462 & 1.507 & 0.207 & 0.028 & 0.497 & 0.031 & 1.383 & 1.985 \\
Mentue & 1.772 & 0.521 & 1.487 & 0.373 & 0.038 & 0.354 & 0.047 & 0.972 & 1.311 \\
Broye & 1.675 & 0.485 & 1.360 & 0.386 & 0.021 & 0.495 & 0.036 & 1.362 & 1.709 \\
Langeten & 1.706 & 0.515 & 1.503 & 0.803 & 0.058 & 0.451 & 0.071 & 1.290 & 1.765 \\
Rietholz & 1.668 & 0.198 & 1.483 & 0.207 & 0.001 & 0.281 & 0.001 & 1.934 & 2.527 \\
Guerbe & 1.644 & 0.488 & 1.369 & 0.309 & 0.025 & 0.444 & 0.031 & 1.419 & 1.970 \\
Biber & 1.516 & 0.347 & 1.077 & 0.143 & 0.009 & 0.348 & 0.018 & 2.257 & 2.998 \\
Kleine Emme & 1.477 & 0.397 & 0.245 & 0.178 & 0.049 & 0.469 & 0.919 & 2.195 & 2.727 \\
Ilfis & 1.695 & 0.446 & 1.465 & 0.240 & 0.198 & 0.583 & 0.283 & 1.915 & 2.424 \\
Sense & 1.572 & 0.498 & 1.328 & 0.208 & 0.027 & 0.478 & 0.046 & 1.619 & 2.128 \\
Alp & 1.350 & 0.213 & 0.861 & 0.117 & 0.004 & 0.290 & 0.010 & 3.544 & 4.233 \\
Emme & 1.561 & 0.357 & 1.133 & 0.113 & 0.325 & 0.728 & 0.432 & 2.439 & 3.025 \\
Sitter & 1.706 & 0.608 & 1.392 & 0.154 & 0.173 & 0.489 & 0.230 & 0.499 & 1.078 \\
Erlenbach & 1.303 & 0.211 & 0.476 & 0.099 & 0.007 & 0.313 & 0.314 & 4.483 & 5.158 \\
Luempenen & 1.346 & 0.280 & 0.467 & 0.155 & 0.019 & 0.428 & 0.374 & 4.665 & 5.366 \\
Grande Eau & 1.522 & 0.457 & 0.626 & 0.376 & 0.104 & 0.459 & 0.746 & 2.609 & 2.988 \\
Schaechen & 1.417 & 0.382 & 1.181 & 0.146 & 0.008 & 0.364 & 0.010 & 3.108 & 3.694 \\
Allenbach & 1.480 & 0.334 & 1.350 & 0.105 & 0.019 & 0.477 & 0.019 & 3.053 & 3.617 \\
Riale di Calneggia & 1.279 & 0.275 & 1.005 & 0.193 & 0.008 & 0.416 & 0.020 & 4.636 & 5.191 \\
Ova da Cluozza & 1.468 & 0.587 & 1.267 & 0.256 & 0.102 & 0.168 & 0.179 & 1.797 & 2.243 \\
Dischma & 1.270 & 0.370 & 1.196 & 0.105 & 0.015 & 0.067 & 0.016 & 2.187 & 2.881 \\
\hline
\end{tabular}
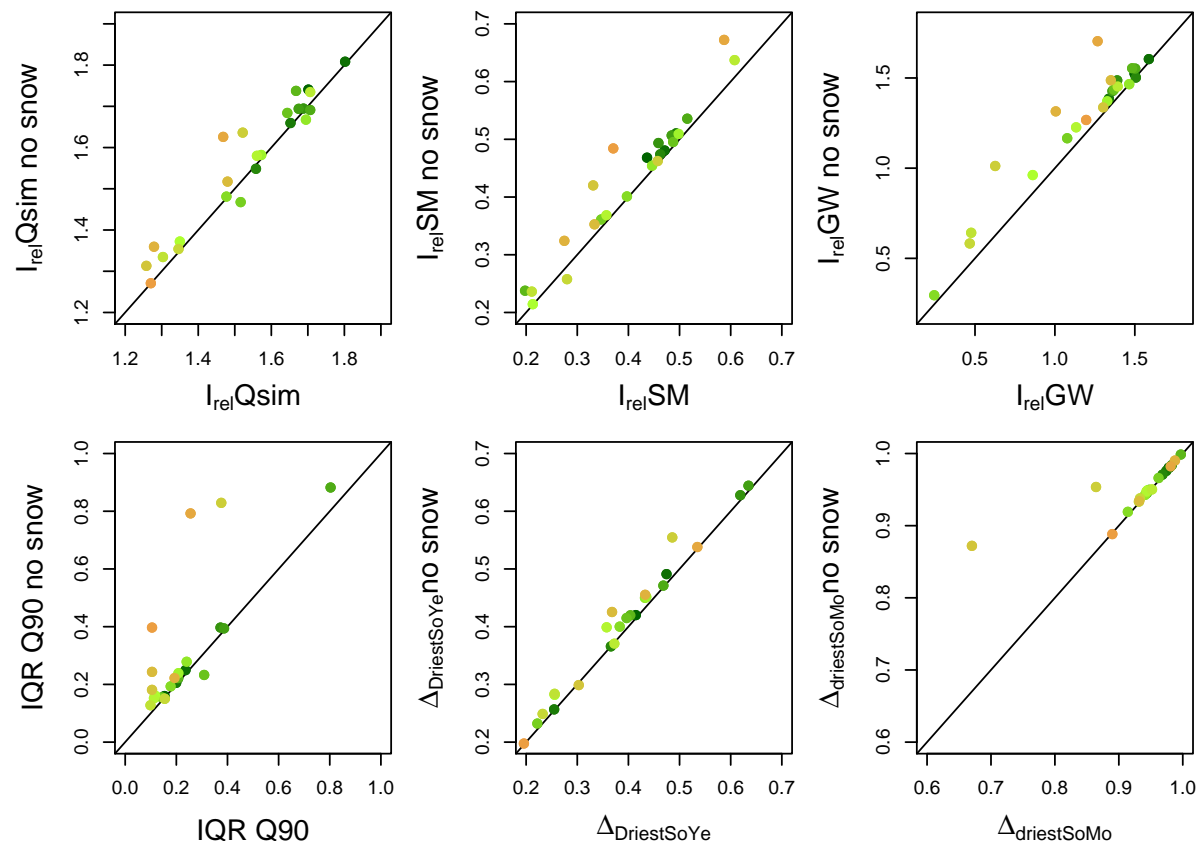

Figure 8. Comparison of the different measures of the sensitivity to drying resulting from simulations in the natural settings and simulations without snow accumulation. The greener colors indicate catchments at (originally) lower mean elevation and the more brownish colors were used for catchments at (originally) higher mean elevation. 
all differences between the catchments. Other explanations for the sensitivity differences with elevation such as larger groundwater storage in higher elevation catchments are indicated by the relationship between groundwater storage and mean catchment elevation.

Hydrogeology could be expected to be correlated to a storage-dependent drought sensitivity (Stahl and Demuth, 1999; Kroll et al., 2004); however, we could not find a clear relationship using hydrogeological productivity with assigned numerical values. It could be that the other controls dominated and hence secondary effects like geology or land use, which are also very diverse and show a high variability among the catchments, did not show any correlation. It also could be that the hydrogeological productivity number was not an appropriate measure for storage and release. The additional test to calibrate the numbers assigned to each productivity class in order to find the highest correlation between drought sensitivity measures and the hydrogeological productivity number yielded a significant correlation between hydrogeology and storage-dependent drought sensitivity. Hence, even with the coarse hydrogeological information on which the hydrogeological productivity number was based it is possible to establish a relationship between drought sensitivity and hydrogeology. The improvement with the calibration and the resulting values for the productivity classes are to some degree dependent on the studied catchments. It would be good in a next step to test this dependency with a larger group of catchments. This is an important task, as the information about hydrogeological productivity could help to better estimate the sensitivity of specific catchments to droughts.

\subsection{Model uncertainties}

The results that are derived from the modeling experiment contain potential sources of uncertainty, i.e., mainly the choice of this hydrological model and its associated structure and parametrization. The uncertainty from the model parametrization was addressed by an ensemble approach, which generated a more robust simulation than would have been the case for single "best" parametrization. Concerning the model structure we can assume that the main indication of the results of the streamflow simulation should be similar for different conceptual hydrological models, whereas we can expect some differences in the simulated storages.

\subsection{Construction of the scenarios}

The simulations from the scenarios clearly depended on the interannual variability of precipitation for each catchment. Hence, we removed the effect of precipitation variability in the analysis by dividing the IQR values by the interquartile range of the precipitation ratio. Following many studies that document the sensitivity of streamflow to climate and climate change, Schaake (1990), Dooge (1992), and Sankara- subramanian et al. (2001) introduced and applied the socalled streamflow elasticity, which describes the sensitivity of streamflow to precipitation. The streamflow elasticity was developed as a robust, unbiased approach that on average and over many applications might discern the true sensitivity of streamflow to climate (Sankarasubramanian et al., 2001). Similar to our approach, the streamflow elasticity is calculated by taking annual streamflow and precipitation into account (Sawicz et al., 2011). In our approach we ensured that the interannual variability of the weather of a catchment would not overprint other catchment properties.

The scenarios were constructed by applying sorted annual or monthly precipitation, while air temperature was not considered explicitly. Null et al. (2010) considered air temperature and analyzed streamflow and in particular low flow sensitivities to climate change by using scenarios with increased temperatures but constant precipitation for mountain catchments. However, the results of previous case studies considering total streamflow response to changes in precipitation and temperature indicated that future total streamflow is more sensitive to precipitation than to temperature (Lettenmaier et al., 1999; Nijssen et al., 2001).

The initial wetness was not considered for the construction of the scenarios but only the annual sums of precipitation, i.e., there might have been a dry year with a wet end of the year. This could lead to actual drier or wetter initial conditions for the following year than expected from the annual sum, particularly for the SoYe scenario. We minimized this effect by using hydrological years starting on 1 October. Still, there could have been a dry summer in an otherwise relatively wet year which then serves as the initial condition for the following year. However, the effect should be low compared to a start in winter with, for instance, a large snow cover at the end of an otherwise dry year.

The scenarios that were used did not aim to be realistic, but should rather give an indication about a general sensitivity to drought. The precipitation in the scenarios decreased intentionally over the course of the years, which causes unnatural autocorrelations. Other studies that use, e.g., GCM outputs of extreme climate change scenarios for climate impact studies keep the natural variation of precipitation from year to year (e.g., Miller et al., 2003; Burke et al., 2006). In our scenarios, potential feedback mechanisms were not considered. A sustained reduction in precipitation would impact potential evaporation and air temperature (e.g., Trenberth et al., 2014) and over the course of decades a shift in vegetation to vegetation adapted to dry conditions could also be expected (e.g., Bréda et al., 2006). Instead, the scenarios in this study were constructed to get an idea of how strongly a catchment would react to a moderate and to an extreme progression of drying in comparison with a sample of other catchments from the temperate humid climate of Switzerland. The scenarios help us to better understand how strongly initial conditions affect hydrological droughts and were appropriately constructed for this purpose. 
As a next step it would be interesting to perform an analysis similar to the one in this study for other regions as well as to find a system of general drivers that make specific catchments vulnerable to droughts or not. A ranking for the different catchments that could (as a starting point) help drought managers to decide which catchments are more vulnerable to droughts can easily be derived from our results. In addition to the scenarios used in this study, there is also the possibility to construct scenarios that have time fractions for sorting that are in between the yearly and the monthly construction of this study, for example, scenarios using half a year, a quarter of a year or 2 months.

\section{Conclusions}

This study demonstrates that hypothetical scenarios can be used to evaluate the sensitivity of catchments to droughts. The response of streamflow as well as soil moisture and groundwater storages to a continuous progression of drying was analyzed both in general as well as focusing on drought characteristics and on one historical drought event. Our analysis showed that mean catchment elevation, size and slope were the main controls on the sensitivity of the catchments to drought. The results suggest that higher elevation catchments with steeper slopes were less sensitive to droughts than lower elevation catchments with less steep slopes, which could not solely be attributed to an increased snow influence. The soil moisture storage was significantly correlated to catchment size, where we found smaller catchments to be less sensitive to droughts than larger catchments. We did not find a clear relationship between drought sensitivity and hydrogeology; however, another choice of the productivity classes would lead to such a relationship. Generally, for water resources management it is important to look at both streamflow sensitivity and storage sensitivity to droughts. With our model-based approach the sensitivity of both can be easily estimated. This approach can serve as a starting point for water resources managers to understand the vulnerability of their catchments.

Acknowledgements. Support from the Swiss National Research Program Sustainable Water Management (NRP 61, project DROUGHT-CH) is gratefully acknowledged. The authors thank FOEN and MeteoSwiss for providing the data used in this study. Many thanks to Tracy Ewen for improving the English of the manuscript. We thank A. F. van Loon as well as an anonymous reviewer for their valuable comments.

Edited by: S. Attinger

\section{References}

Aviolat, P., Bitterli, T., Brändli, R., Christe, R., Fracheboud, S., Frei, D., George, M., Matousek, F., and Tripet, J.-P.: Hydrological Atlas of Switzerland, plate 8.6, Groundwater resources, Federal office for Water and Geology, Berne, 2004.

Bergström, S.: The HBV model, in: Chapter 13, Computer Models of Watershed Hydrology, edited by: Singh, V. P., Water Resources Publications, Highlands Ranch, Colorado, USA, 443476, 1995.

Bréda, N., Huc, R., Granier, A., and Dreyer, E.: Temperate forest trees and stands under severe drought: a review of ecophysiological responses, adaptation processes and long-term consequences, Ann. Forest Sci., 63, 625-644, 2006.

Burke, E. J., Brown, S. J., and Christidis, N.: Modeling the recent evolution of global drought and projections for the twenty-first century with the Hadley Centre climate model, J. Hydrometeorol., 7, 1113-1125, 2006.

Dooge, J. C.: Sensitivity of runoff to climate change: A Hortonian approach, B. Am. Meteorol. Soc., 73, 2013-2024, 1992.

Eltahir, E. A. and Yeh, P. J.-F.: On the asymmetric response of aquifer water level to floods and droughts in Illinois, Water Resour. Res., 35, 1199-1217, 1999.

Fleig, A. K., Tallaksen, L. M., Hisdal, H., and Demuth, S.: A global evaluation of streamflow drought characteristics, Hydrol. Earth Syst. Sci., 10, 535-552, doi:10.5194/hess-10-535-2006, 2006.

FOEN: Federal Office for the Environment, section of hydrology, http://www.bafu.admin.ch/hydrologie/12385/index.html?lang= en (last access: 10 December 2013), 2013a.

FOEN: Federal Office for the Environment, section of hydrology, http://www.hydrodaten.admin.ch/en/ (last access: 20 December 2013), 2013b.

Frei, C.: Interpolation of temperature in a mountainous region using nonlinear profiles and non-Euclidean distances, Int. J. Climatol., 34, 1585-1605, 2013.

Kohn, I., Rosin, K., Freudiger, D., Belz, J. U., Stahl, K., and Weiler, M.: Low flow in Germany in 2011, Hydrol. Wasserwirt., 58, 417, 2014.

Kroll, C., Luz, J., Allen, B., and Vogel, R. M.: Developing a watershed characteristics database to improve low streamflow prediction, J. Hydrol. Eng., 9, 116-125, 2004.

Lehner, B., Döll, P., Alcamo, J., Henrichs, T., and Kaspar, F.: Estimating the impact of global change on flood and drought risks in Europe: a continental, integrated analysis, Climatic Change, 75, 273-299, 2006.

Lettenmaier, D. P., Wood, A. W., Palmer, R. N., Wood, E. F., and Stakhiv, E. Z.: Water resources implications of global warming: A US regional perspective, Climatic Change, 43, 537-579, 1999.

Li, J., Cook, E., Chen, F., Gou, X., D’Arrigo, R., and Yuan, Y.: An extreme drought event in the central Tien Shan area in the year 1945, J. Arid Environ., 74, 1225-1231, 2010.

Lindström, G.: A simple automatic calibration routine for the HBV model, Nord. Hydrol., 28, 153-168, 1997.

Lindström, G., Johansson, B., Persson, M., Gardelin, M., and Bergström, S.: Development and test of the distributed HBV-96 hydrological model, J. Hydrol., 201, 272-288, 1997.

MeteoSwiss: Federal Office of Meteorology and Climatology, http://www.meteoschweiz.admin.ch/web/en/services/data portal/gridded_datasets.html, last access: 10 October 2013. 
Miller, N. L., Bashford, K. E., and Strem, E.: Potential impacts of climate change on california hydrology, J. Am. Water Resour. Assoc., 39, 771-784, 2003.

Mishra, A. K. and Singh, V. P.: A review of drought concepts, J. Hydrol., 391, 202-216, 2010.

Nijssen, B., O’Donnell, G. M., Hamlet, A. F., and Lettenmaier, D. P.: Hydrologic sensitivity of global rivers to climate change, Climatic change, 50, 143-175, 2001.

Null, S. E., Viers, J. H., and Mount, J. F.: Hydrologic response and watershed sensitivity to climate warming in California's Sierra Nevada, PLoS One, 5, e9932, doi:10.1371/journal.pone.0009932, 2010.

Peters, E., Torfs, P., Van Lanen, H., and Bier, G.: Propagation of drought through groundwater - a new approach using linear reservoir theory, Hydrol. Process., 17, 3023-3040, 2003.

Rebetez, M., Mayer, H., Dupont, O., Schindler, D., Gartner, K., Kropp, J. P., and Menzel, A.: Heat and drought 2003 in Europe: a climate synthesis, Ann. Forest Sci., 63, 569-577, 2006.

Sankarasubramanian, A., Vogel, R. M., and Limbrunner, J. F.: Climate elasticity of streamflow in the United States, Water Resour. Res., 37, 1771-1781, 2001.

Santos, J., Corte-real, J., and Leite, S.: Atmospheric large-scale dynamics during the 2004/2005 winter drought in portugal, Int. J. Climatol., 27, 571-586, 2007.

Sawicz, K., Wagener, T., Sivapalan, M., Troch, P. A., and Carrillo, G.: Catchment classification: empirical analysis of hydrologic similarity based on catchment function in the eastern USA, Hydrol. Earth Syst. Sci., 15, 2895-2911, doi:10.5194/hess-15-28952011, 2011.

Schaake, J. C.: From climate to flow, inClimate Change and U.S. Water Resources, in: chap. 8, edited by: Waggoner, P. E., John Wiley, New York, 177-206, 1990.

Seibert, J.: Regionalisation of parameters for a conceptual rainfallrunoff model, Agr. Forest Meteorol., 98, 279-293, 1999.

Seibert, J.: Multi-criteria calibration of a conceptual runoff model using a genetic algorithm, Hydrol. Earth Syst. Sci., 4, 215-224, doi:10.5194/hess-4-215-2000, 2000

Seibert, J. and Vis, M. J. P.: Teaching hydrological modeling with a user-friendly catchment-runoff-model software package, Hydrol. Earth Syst. Sci., 16, 3315-3325, doi:10.5194/hess-16-33152012, 2012.

Solomon, S.: Climate change 2007 - the physical science basis: Working group I contribution to the fourth assessment report of the IPCC, vol. 4, Cambridge University Press, 2007.

Stahl, K. and Demuth, S.: Linking streamflow drought to the occurrence of atmospheric circulation patterns, Hydrolog. Sci. J., 44, 467-482, 1999
Tallaksen, L. M. and Van Lanen, H. A.: Hydrological Drought: Processes and Estimnation Methods for Streamflow and Groundwater, vol. 48, Elsevier, Amsterdam, the Netherlands, 2004.

Teutschbein, C. and Seibert, J.: Bias correction of regional climate model simulations for hydrological climate-change impact studies: Review and evaluation of different methods, J. Hydrol., 456 , 12-29, 2012.

Teutschbein, C. and Seibert, J.: Is bias correction of regional climate model (RCM) simulations possible for nonstationary conditions?, Hydrol. Earth Syst. Sci., 17, 5061-5077, doi:10.5194/hess-17-5061-2013, 2013.

Trenberth, K. E., Dai, A., van der Schrier, G., Jones, P. D., Barichivich, J., Briffa, K. R., and Sheffield, J.: Global warming and changes in drought, Nat. Clim. Change, 4, 17-22, 2014.

Trigo, R. M., Gouveia, C. M., and Barriopedro, D.: The intense 2007-2009 drought in the Fertile Crescent: Impacts and associated atmospheric circulation, Agr. Forest Meteorol., 150, 12451257, 2010.

Van Loon, A. F. and Van Lanen, H. A. J.: A process-based typology of hydrological drought, Hydrol. Earth Syst. Sci., 16, 19151946, doi:10.5194/hess-16-1915-2012, 2012.

Van Loon, A. F., van Lanen, H. A., Hisdal, H., Tallaksen, L. M., Fendeková, M., Oosterwijk, J., Horvát, O., and Machlica, A.: Understanding hydrological winter drought in Europe, Global Change: Facing Risks and Threats to Water Resources, IAHS Publ., 340, 189-197, 2010.

Wang, G.: Agricultural drought in a future climate: results from 15 global climate models participating in the IPCC 4th assessment, Clim. Dynam., 25, 739-753, 2005.

Wetherald, R. T. and Manabe, S.: Detectability of summer dryness caused by greenhouse warming, Climatic Change, 43, 495-511, 1999.

Wetherald, R. T. and Manabe, S.: Simulation of hydrologic changes associated with global warming, J. Geophys. Res., 107, 4379, doi:10.1029/2001JD001195, 2002.

Wilby, R. L. and Harris, I.: A framework for assessing uncertainties in climate change impacts: Low-flow scenarios for the River Thames, UK, Water Resour. Res., 42, W02419, doi:10.1029/2005WR004065, 2006.

Zaidman, M. D., Rees, H. G., and Young, A. R.: Spatio-temporal development of streamflow droughts in north-west Europe, Hydrol. Earth Syst. Sci., 6, 733-751, doi:10.5194/hess-6-733-2002, 2002. 